\title{
GENERICITY AND MINIMAX OPTIMIZATION
}

\author{
ALEXANDER J. ZASLAVSKI
}

\begin{abstract}
In this paper we study a class of minimax problems $\max \{f(x), g(x)\} \rightarrow \min , x \in R^{n}$ where $f, g \in C^{1}\left(R^{n}\right)$ and $f$ is convex. We show that the subclass of all problems for which there exists a point of minimum $z \in R^{1}$ such that $f(z)=g(z)$ and $\nabla f(z)=\nabla g(z)$ is small.
\end{abstract}

Mathematics subject classification (2000): 49J35, 54E52.

Key words and phrases: Complete metric space, generic property, minimax problem.

\section{REFERENCES}

[1] A. Cellina, C. Mariconda, The existence question in the calculus of variations: A density result, Proc. Amer. Math. Soc. 120 (1994), 1145-1150.

[2] F. S. DE BLASI, J. MYJAK, Generic flows generated by continuous vector fields in Banach spaces, Adv. in Math. 50 (1983), 266-280.

[3] V. F. Demyanov, V. L. VASIL'EV, Nondifferentiable Optimization. Translations Series in Mathematics and Engineering, Optimization Software, Inc., New York, 1985.

[4] V. F. Demyanov, V. N. Malozemov, Introduction to Minimax, Dover Publications, Inc., New York, 1990.

[5] V. F. Demyanov, A. M. Rubinov, Constructive Nonsmooth Analysis, Peter Lang, Frankfurt am Main, 1995.

[6] J. L. Kelley, General topology, Van Nostrand, Princeton NJ, 1955.

[7] S. REICH, A. J. ZASLAVSKI, Convergence of generic infinite products of nonexpansive and uniformly continuous operators, Nonlinear Analysis: Theory, Methods and Applications 36 (1999), 1049-1065.

[8] A. M. RUBINOV, A. J. ZASLAVSKI, Two porosity results in monotonic analysis, Numerical Functional Analysis and Optimization 23 (2002), 651-668.

[9] A. J. ZASLAVSKI, Generic well-posedness of optimal control problems without convexity assumptions, SIAM J. Control Optim. 39 (2000), 250-280. 